32

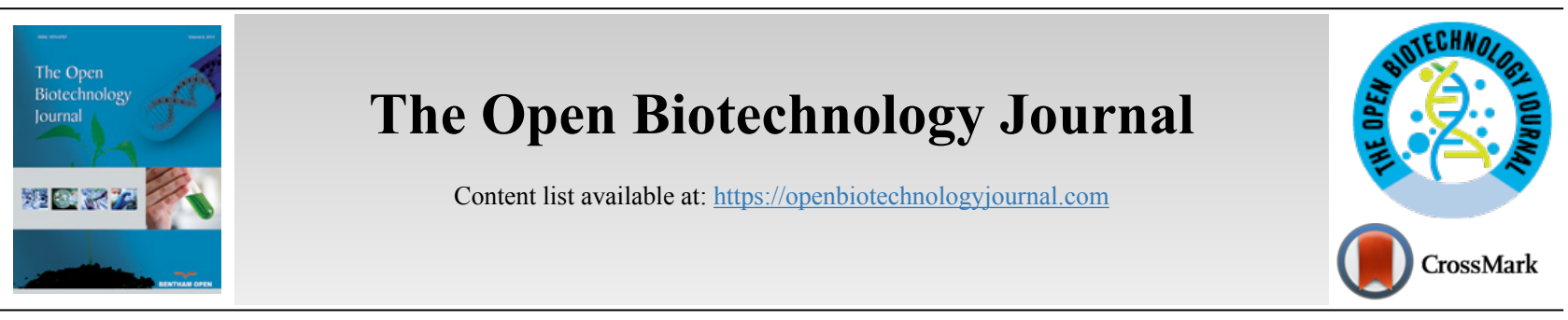

RESEARCH ARTICLE

\title{
Citric Acid Production by the Solid-State Cultivation Consortium of Aspergillus Niger and Trichoderma Reesei from Sugarcane Bagasse
}

\author{
Reinaldo G. Bastos, ${ }^{1, *}$ and Hiléia C. Ribeiro ${ }^{1}$ \\ ${ }^{l}$ Center of Agricultural Sciences, Federal University of São Carlos, São Carlos, São Paulo, Brazil.
}

\begin{abstract}
:
Aims:

The aim of this research was to evaluate the SSC of Aspergillus niger and Trichoderma reesei alone and in consortium for the citric acid production from sugarcane bagasse.

Methods:

Solid-State Cultivation (SSC) is characterized by microbial growth on solid supports often agroindustrial by-products in the near absence of free water conditions. Citric acid, an important by-product used in various sectors of the economy, can be obtained from the SSC using sugarcane bagasse, minimizing the cost of its production with the use of this industrial by-product.

Results:

The fungal consortiums have advantages over the isolated cultures, highlighting the best use of substrates due to enzyme supplementation, especially hydrolases.

Conclusion:

The results indicated a specific production of citric acid of $2.51 \mathrm{mg}$ per $\mathrm{g}$ of biomass per hour, which was higher than that obtained when using the two fungi alone.
\end{abstract}

Keywords: Solid-state cultivation, Sugarcane bagasse, Microbial consortium, Citric acid, Aspergillus niger, Trichoderma reesei.

\begin{tabular}{|l|l|l|r|}
\hline Article History & Received: November 11, 2019 & Revised: December 18, 2019 & Accepted: January 27, 2020
\end{tabular}

\section{INTRODUCTION}

Solid-State Cultivation (SSC) may be defined as the microbial growth on solid supports in conditions of the absence of free water, i.e., similar to the occurrence of fungi found in nature [1]. This process has been highlighted in chemical, food, pharmaceutical and agricultural industries as it requires little power, produces low-waste and reuses industrial residues as substrates having advantages when compared to submerged fermentation as it produces more concentrated product and higher yield in some metabolites [2]. Among the many microorganisms that can be grown from solid supports, those distinguished by filamentous fungi have the best ability to grow in these conditions due to their physiological and biochemical characteristics [3]. After phycomycetes (Mucor

\footnotetext{
* Address correspondence to this author at the Center of Agricultural Sciences, Federal University of São Carlos, Sao Carlos, Sao Paulo, Brazil; Tel: +551935432584; E-mail: reinaldo.bastos@ufscar.br
}

and Rhizopus), ascomycetes (Aspergillus, Penicillium and Trichoderma); basidiomycetes (Polysporus) and hyphomicetes (Dreschslera) are the most studied classes [4 - 6].

Literature data foment that fungal consortia have advantages over the use of unique cultures because they better use the substrate leading to higher incomes and are better adapted and more resistant to contamination by other microorganisms due to the synergistic interactions that occur between them [7]. There are reports that in lignocellulolytic microorganisms, they naturally interact in mixed cultures to degrade cellulose, occur without competition for nutrients and that they are compatible partners [8]. A known example of the association between fungi in biotechnology processes is the use of Trichoderma reesei and Aspergillus niger for the production of hydrolytic enzymes. However, there is a lack of knowledge about this consortium of citric acid from byproducts SSC. $A$. niger is the fungi most widely used in industrial terms by 
submerged aerobic cultivation from conventional carbon sources [9, 10].

Used mainly by the food and pharmaceutical industries, citric acid is the second most- produced microbial metabolite in the world [11]. Its global production is upwards of 1.7 million tons per year, affecting an annual 5\% increase in its demand, which makes it necessary to develop new processes for obtaining this molecule [12, 13].

Although most of the citric acid is produced by A. niger in submerged fermentation processes using solid state growth, it has been gaining momentum and the use of lignocellulosic agricultural residues, such as bagasse from sugarcane, which has been proven to be effective in research [3].

In this sense, the present study evaluated the citric acid production of isolated cultures of Trichoderma reesei and Aspergillus niger, as well as its consortium in the cultivating of SSC from sugarcane bagasse.

\section{MATERIALS AND METHODS}

\subsection{Inoculum}

The strains of Trichoderma reesei CMA and Aspergillus niger CCT 4355 were maintained in a PDA medium at $4{ }^{\circ} \mathrm{C}$ [9] in the Center for Agricultural Sciences (CCA), Federal University of São Carlos (UFSCar), Araras, Brazil. The fungi were propagated in flasks for seven days in a synthetic medium and the spore suspension was characterized in terms of total carbon and nitrogen in TOC-LCPN SHIMADZU ${ }^{\circledR}$.

\subsection{Bagasse Sugarcane}

The bagasse sugarcane used in the experiments was collected from sugarcane processing industry located in the region of Araras, Brazil, and stored in LABMAC/CCA/ UFSCar. The particles of sugarcane bagasse were classified through a series of Tyler sieves, those selected were retained in the 14 and $28 \mathrm{Mesh}$, corresponding to average diameter range of 1.17 and $0.59 \mathrm{~mm}$, these were subsequently sterilized in polypropylene bags.

\subsection{SSC in a Packed-Bed Column Bioreactor}

SSCs were set up in a conventional packed-bed column bioreactor with a $30 \mathrm{~mm}$ diameter and a $60 \mathrm{~mm}$ bed height (Fig. 1) at $25^{\circ} \mathrm{C}$, with up-flow aeration of $0.2 \mathrm{~L} \mathrm{~min}^{-1}$ with water saturated with air by a humidifier [14]. In this context, experiments were conducted with a suspension of spores of Aspergillus niger, Trichoderma reesei and consortium of them, about $50 \%$ (volume) of moisture solution, with and without the addition of sucrose $\left(10 \mathrm{~g} \mathrm{~L}^{-1}\right)$ in the liquid impregnating the particles.

The kinetic process was evaluated during the 7-day sample by analysis of the solid medium and fungal extract. In the solid medium, the moisture by dry weight was determined gravimetrically. The fungal extract was obtained with deionized water in the ratio of 1:15 (solid-solvent), and then the same amount of acetone was added. Each stage lasted 45 minutes in an orbital shaker at $100 \mathrm{rpm}$ and $28^{\circ} \mathrm{C}$, according to the conditions adapted and optimized by our research group [12, 14].
Raw fungal extract obtained from each analysis had its $\mathrm{pH}$ characterized by potentiometry. The glucose content was determined by the glucose oxidase enzyme method - peroxidase $\left(\right.$ LABORLAB ${ }^{\circledR}$ ), citric acid by colorimetric reaction with pyridine and acetic anhydride using the IN VITRO ${ }^{\circledR}$ commercial kit and carbon and nitrogen balance in a Carbon and Nitrogen Analyzer TOC -LCPN SHIMADZU ${ }^{\circledR}$.

The highest citric acid productivity $\left(\operatorname{Prod}_{\text {máx }}\right)$ was calculated considering the maximum concentration obtained in the timeframe. The specific rate of citric acid production $\left(\mu_{\mathrm{P}}\right)$ was calculated considering the relationship between $\operatorname{Prod}_{\text {max }}$ and the amount of biomass, considering the elemental formula $\mathrm{CH}_{1,72} \mathrm{O}_{0,55} \mathrm{~N}_{0,17}$ for two fungi [15]. Furthermore, the total nitrogen concentration was determined in the TOC -LCPN SHIMADZU $^{\circledR}$.

\section{RESULTS AND DISCUSSION}

\subsection{SSC of Aspergillus niger in Sugarcane Bagasse}

Experiments in the packed bed column type bioreactor were first conducted with inoculum consisting of only Aspergillus niger suspension. According to Fig. (2), it was found that the highest yield of citric acid occurred after 4 days of culture $\left(103.45 \mathrm{mg} \mathrm{L}^{-1}\right)$ in the initial condition without addition of sucrose. As the measurement of the evolution of biomass in SSC is complex due to the difficulty of separating the solid support of cells, citric acid being partially linked to growth product can only indicate fungal growth. Currently, this microorganism is extensively used in the industrial production of citric acid, especially in submerged cultivation from sucrose [16]. Even so, the result indicates a high yield even without the presence of sucrose, probably having the hydrolysis of the structural components from the residue with the subsequent synthesis of citric acid. In this regard, Fig. (3) shows glucose profiles in the SSC of $A$. niger in sugarcane bagasse with and without the addition of sucrose. According to the results, in the tests with the addition of sucrose a peak of glucose in the early hours was found, indicating possible hydrolysis of this disaccharide generating monomeric units followed by a substantially constant consumption up to 7 days. Moreover, such initial behavior was not observed for the tests without the addition of sucrose, with about two days after the maintenance of the glucose content (pseudo steady-state) due to consumption and formation from the hydrolysis of the structural polysaccharides. This glucose profile is supported by other research studies, considering the low content of naturally occurring monosaccharides in sugarcane bagasse [17].

Citric acid production depends on the control of key parameters such as the availability of carbon, nitrogen, moisture and an optimum $\mathrm{pH}$ range [18]. In this sense, Fig. (4) shows the profiles of Total Organic Carbon (TOC), Total Nitrogen (TN), the solid medium moisture and $\mathrm{pH}$ for the SSC fungal extract obtained from $A$. niger in sugarcane bagasse with and without adding sucrose. The results indicate a carbon balance in the fungal extract, since substrates were converted into metabolites such as citric acid, calculated in determining the TOC. However, the TN profiles indicate a discrete higher growth for the condition without adding sucrose, suggesting 
that fungal hydrolases were instrumental in glucose release, as already illustrated in Figs. (2 and 3). This phenomenon can also be seen in Fig. (4C), where a slightly higher moisture content was observed in the experiment without the addition of glucose, which usually indicates metabolic water production and more intense fungal growth. Water mass balance of solidstate cultivation can be described by Eq. (1) [19]:

$$
\frac{d X_{W}}{d t}=R_{W}-E+\frac{F_{w} \quad W_{p}}{M_{S}}-\frac{X_{W}}{M_{S}} \frac{d M_{S}}{d t}
$$

Where $\mathrm{R}_{\mathrm{W}}$ is the metabolic water production rate [g water/g solid.h]; E represents the water loss due to evaporation [g water/g solid.h]; $\mathrm{F}_{\mathrm{w}}$ is the amount added in the solid medium; $\mathrm{W}_{\mathrm{P}}$ is the amount of water loss in the bottom of the column; $\mathrm{M}_{\mathrm{S}}$ is mass of solid medium. Whereas sugarcane bagasse is the solid support, no addition of water during the process and the evaporation losses are negligible due to the condensation column, we have Eq. (2):

$$
\frac{d X_{W}}{d t}=R_{W}-\frac{X_{W}}{M_{S}} \frac{d M_{S}}{d t}
$$

Therefore, considering the water mass balance proposed by the equations described, until the second day of the experiment there is a relative moisture that is substantially constant for both conditions due to the residue of degradation for the release of glucose, there was water consumption from the hydrolysis and production of water due to the respiratory metabolism of the fungi. Thus, the reaction term Eq. (2) were similar, there was no significant accumulation. After this period, the production word $\left(\mathrm{R}_{\mathrm{w}}\right)$ was slightly higher due to the more intense microbial growth and due to the degradation of the solid medium, bringing the moisture content virtually, highlighted in the cultivation without additional sucrose. Higher moisture solid mediums can be inconvenient because they lead to a reduction in the porosity of the particle bed and hence limit oxygen transfer [20]. Moreover, SSC is, by definition, microbial growth on solid matrices in conditions of the absence of free water [1]. Thus, if the moisture in the solid medium varies widely in order to have a tendency for medium water accumulation in the final days of cultivation, the physical characteristics of CES were changed, generating a hybrid system between the solid and submerged states with losses by mass transfer. However, in this paper the results point to maximum moisture of $85 \%$, which is below the maximum capacity of the particles' water absorption. This guaranteed the absence of free water in the system and the citric acid production can be attributed to an increase in solids. About $\mathrm{pH}$, it is noted that in the tests with the addition of sucrose, there was a decreased value during the first hours, staying at around 4.3. On the other hand, the $\mathrm{pH}$ of the crude extract remained at around 5 throughout the sampling period in the tests without the addition of sucrose, a value more suitable for fungal growth, which might also have influenced the higher production of citric acid.

Another point to be noted is that the tests do not occur in axenic conditions and that, despite the occurrence of bacteria contamination be far less significant than in submerged processes due to lower water availability, this cannot be ruled out. Thus, such contamination could have been more significant in the condition with sucrose in the medium, leading to a reduction in the $\mathrm{pH}$ due to the production of other organic acids, which are common products of fermentation by bacteria reduction of pyruvate.

In this context, the results indicate the feasibility for the production of citric acid by Aspergillus niger in packed-bed columns using sugarcane bagasse as the natural support of the experimental conditions, i.e. without the addition of other sources of carbon and nutrients.

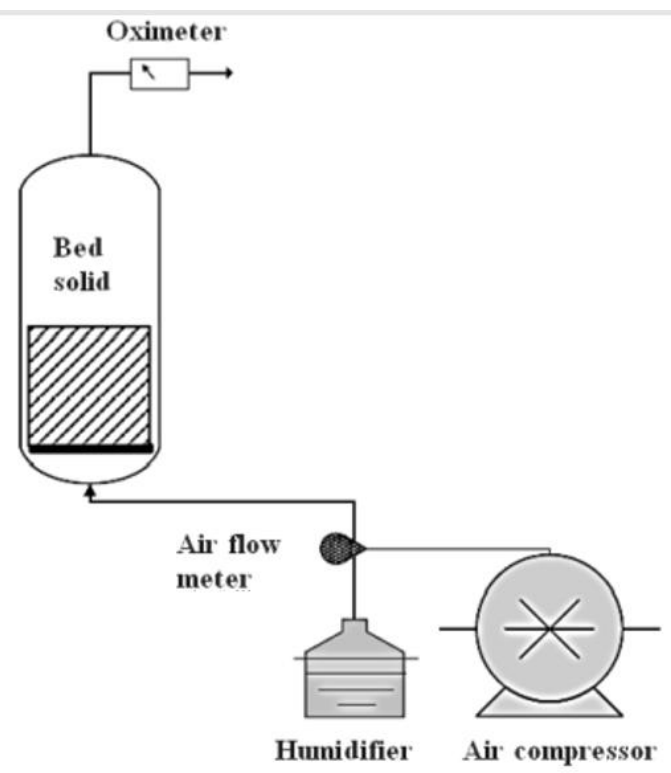

Fig. 1. Schematic experimental system of packed-bed column bioreactor (adapted by Bastos et al. 2014). 


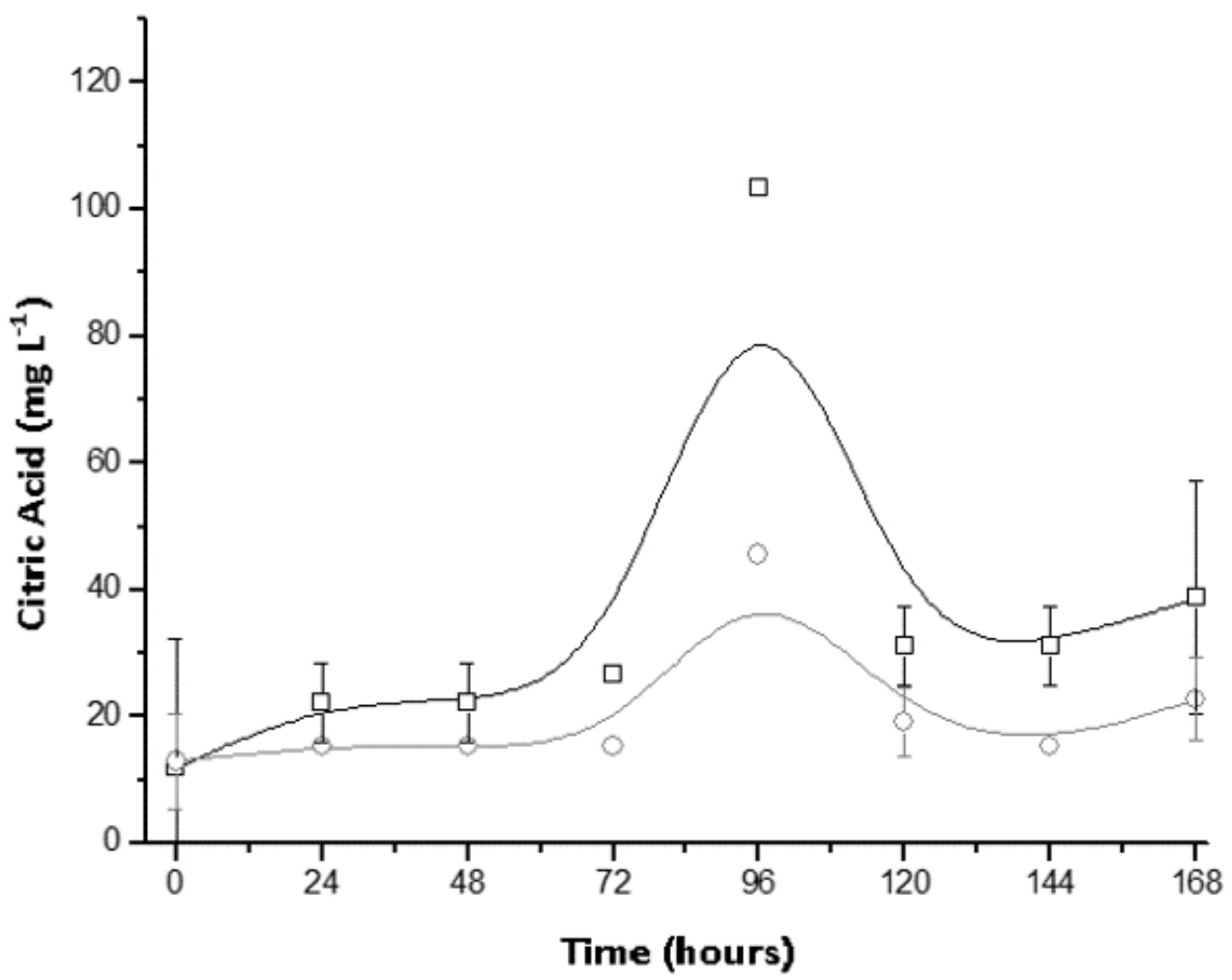

Fig. (2). Citric acid profiles during SSC of A. niger in sugarcane bagasse with (०) and without sucrose addition ( $\square$ ).

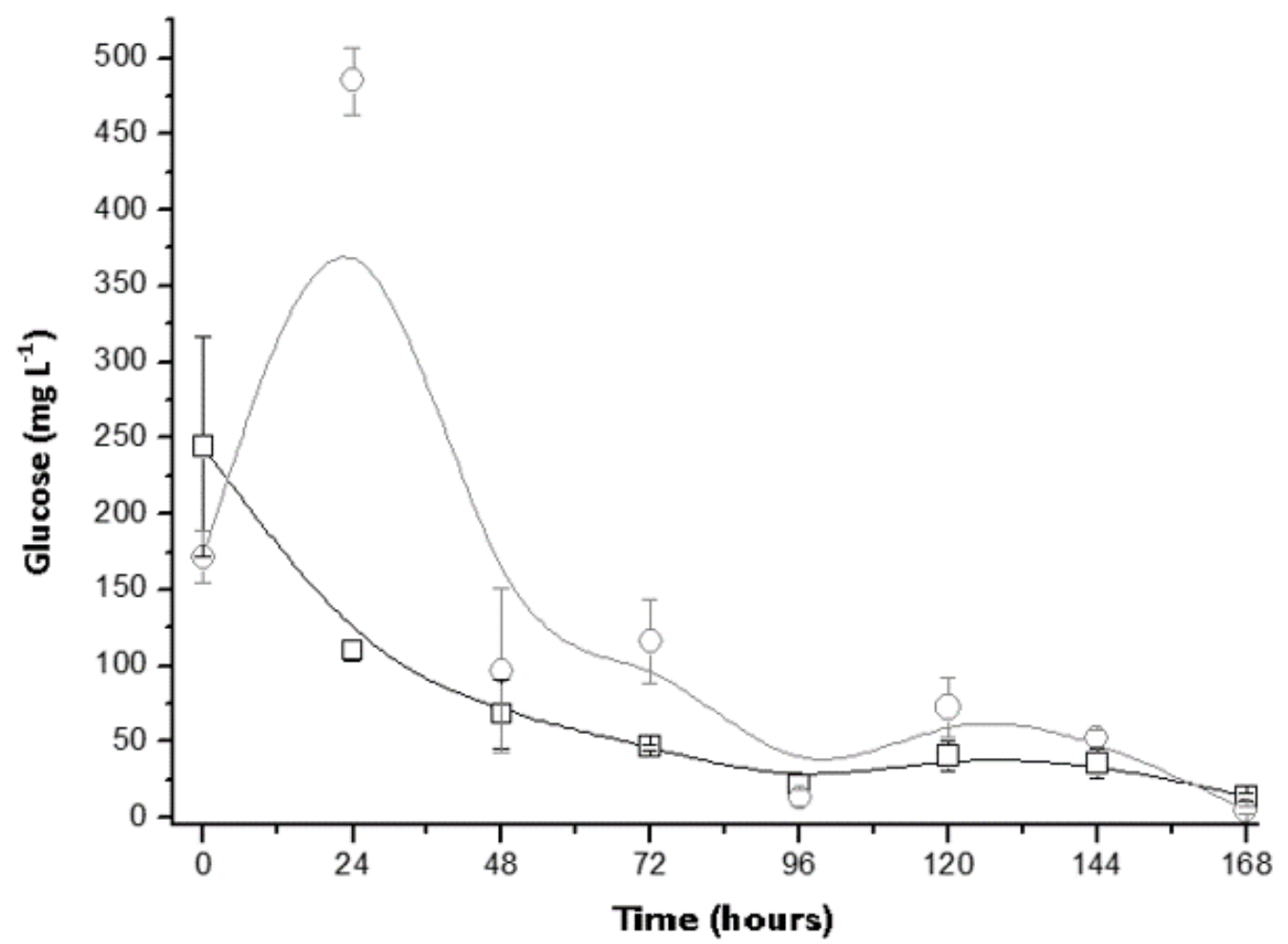

Fig. (3). Glucose profiles during SSC of A. niger in sugarcane bagasse with (०) and without sucrose addition ( $\square$ ). 


\subsection{SSC of Trichoderma reesei in Sugarcane Bagasse}

In tests carried out with Trichoderma reesei in packed-bed columns with sugarcane bagasse it was found that the maximum citric acid concentration was lower than the tests performed with Aspergillus niger (57.58 $\mathrm{mg} \mathrm{L}^{-1}$ ), although it does occur in 3 days of cultivation and for the condition with the addition of sucrose (Fig. 5). Moreover, the glucose concentration decreased within 96 hours for both initial conditions, increasing after 120 hours with no sucrose in the experiment and after 168 hours in the experiment with sucrose remaining above $100 \mathrm{mg} \mathrm{L}^{-1}$. The results indicate that $T$. reesei

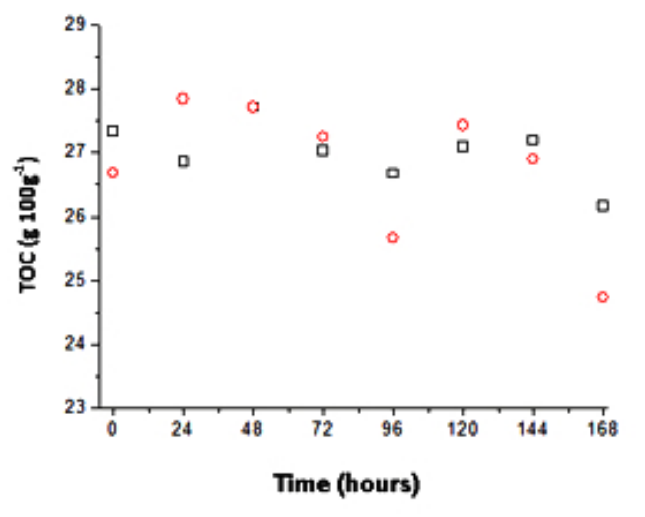

(A)

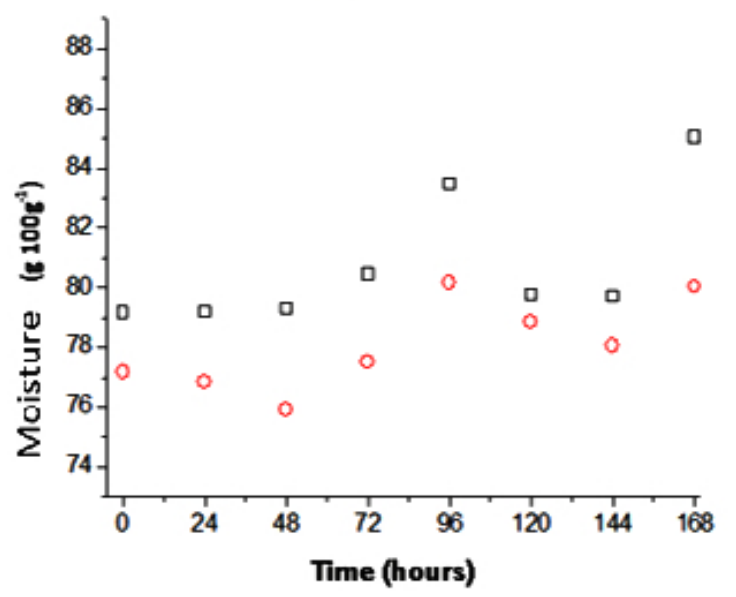

(C) releases higher amounts of glucose in the medium compared to A. niger, probably due to the high structural and biological diversity of this fungus, recognized by the production of various hydrolytic enzymes, especially cellulases (Fig. 6).

According to Fig. (7), profiles of carbon, nitrogen, solid moisture and $\mathrm{pH}$ of fungal extract for $T$. reesei did not differ from the tests with $A$. niger. In fact, the profiles tended to show a slight variation during the 7 days of sampling, a nitrogen and moisture content slightly lower for this fungus was highlighted, suggesting slower growth in the bagasse of sugarcane. Furthermore, the $\mathrm{pH}$ did not show a sharp decrease due to the decreased production of organic acids.

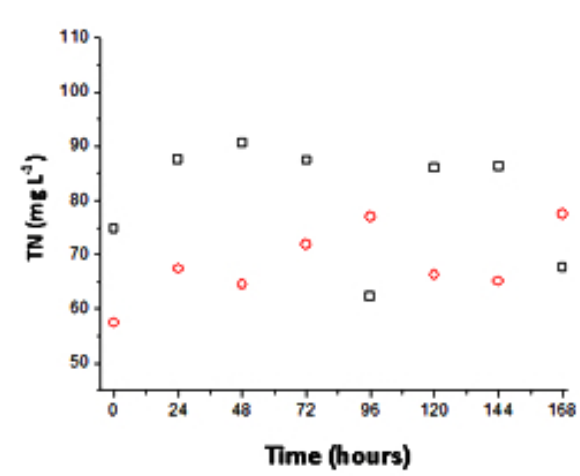

(B)

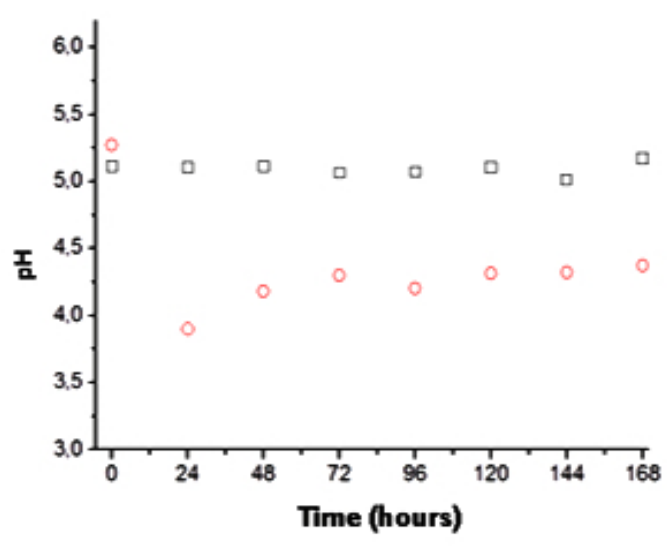

(D)

Fig. (4). TOC (A), TN (B), moisture (C) and pH of fungal extract (D) profiles during SSC of A. niger in sugarcane bagasse with (O) and without sucrose addition $(\square)$. 


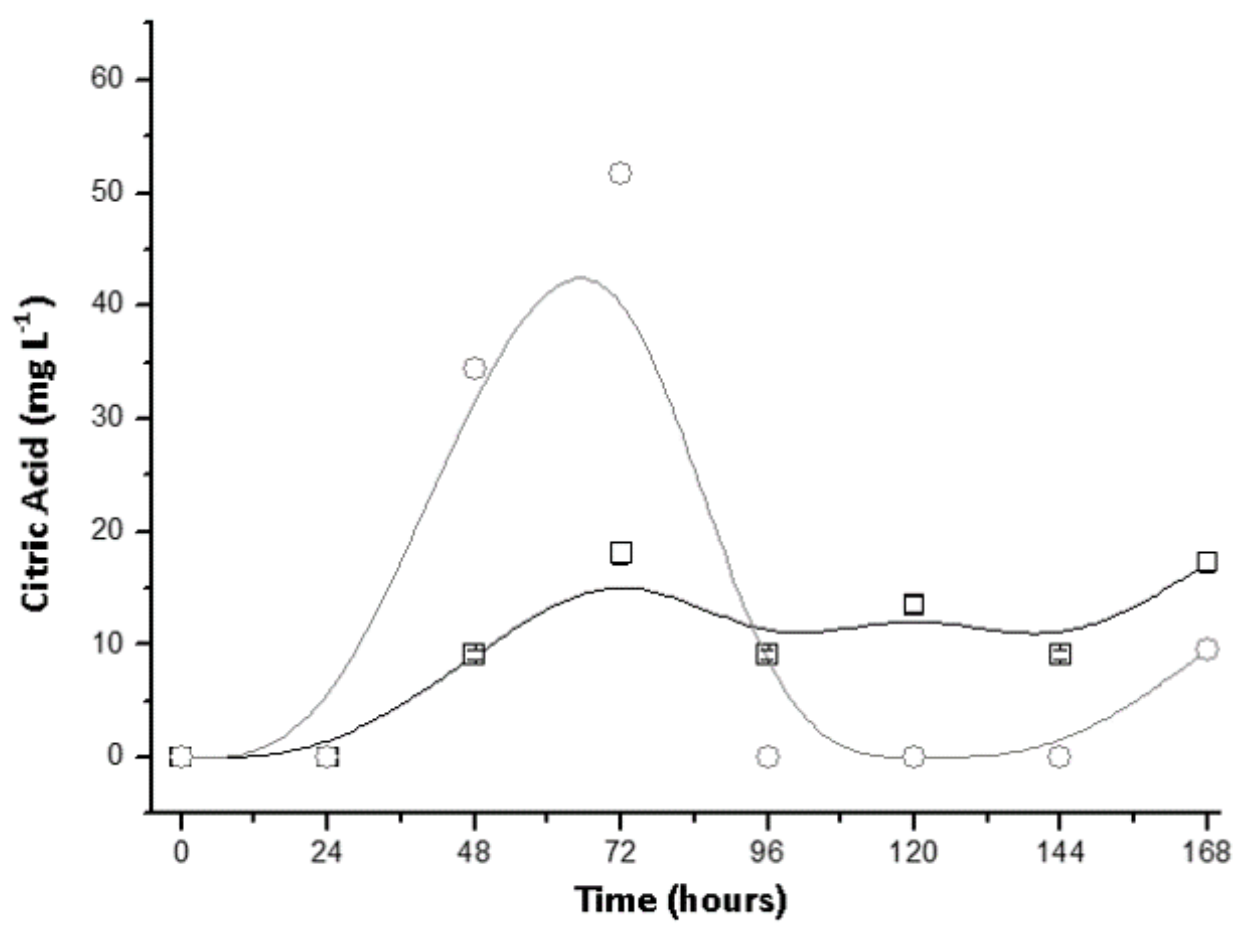

Fig. (5). Citric acid profiles during SSC of T. reesei in sugarcane bagasse with (०) and without sucrose addition (口).

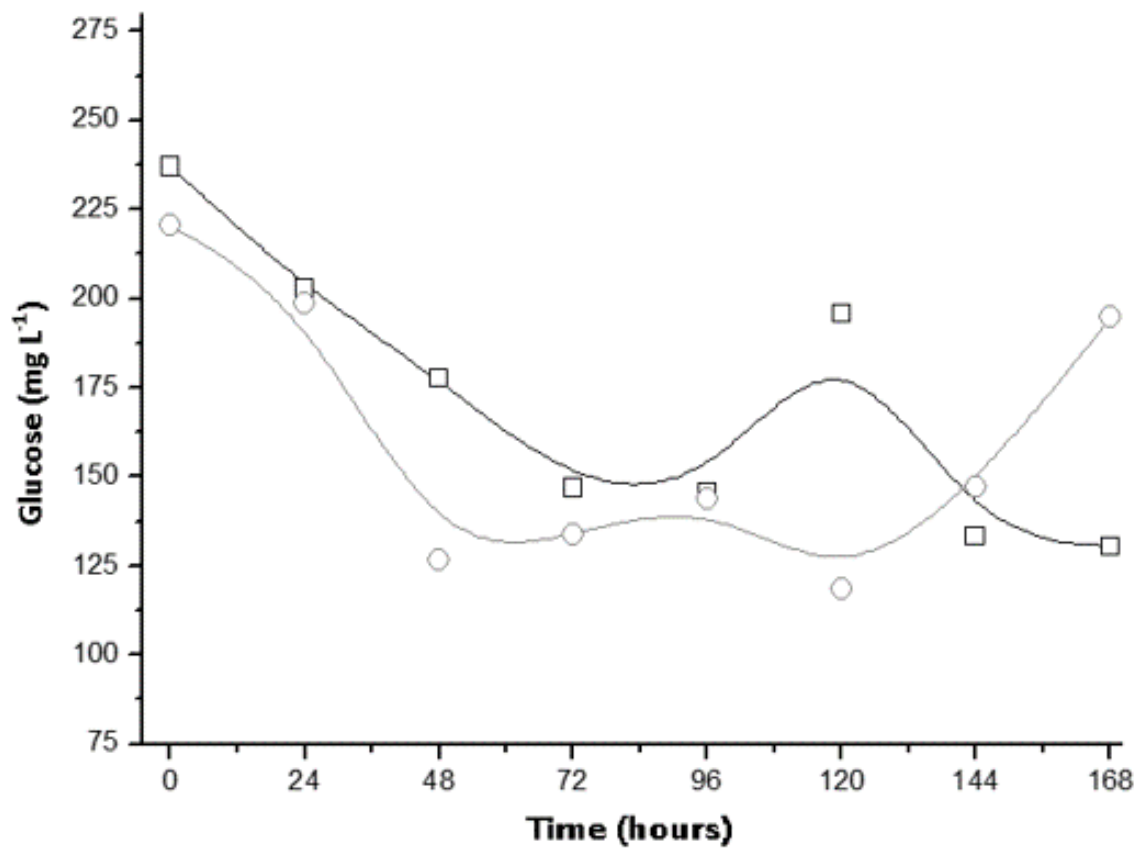

Fig. (6). Glucose profiles during SSC of T. reesei in sugarcane bagasse with (०) and without sucrose addition ( $\square$ ). 


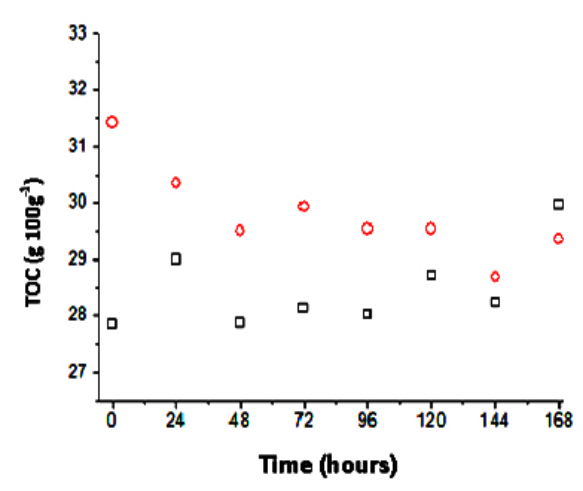

(A)

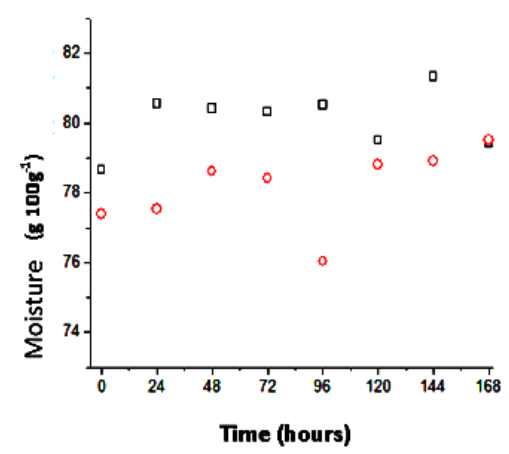

(C)

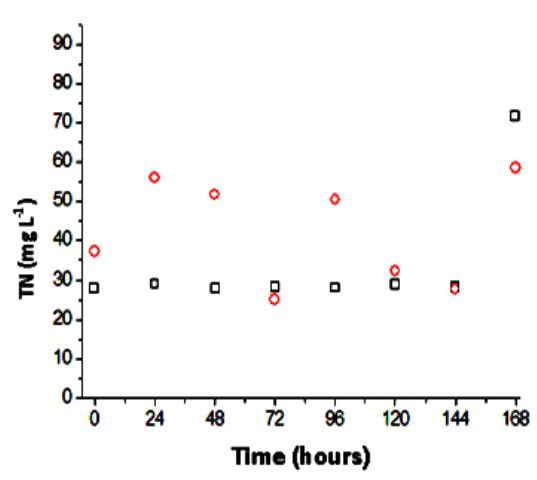

(B)

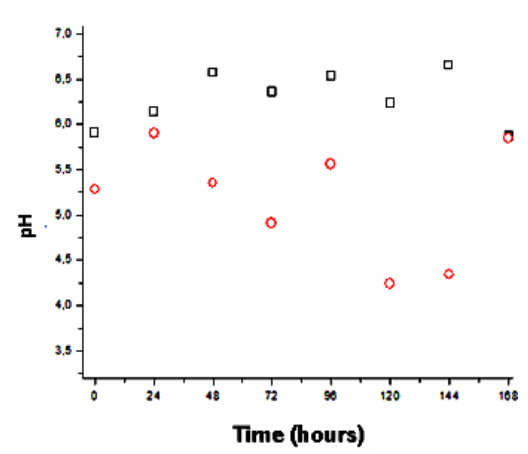

(D)

Fig. (7). TOC (A), TN (B), moisture (C) and pH of fungal extract (D) profiles during SSC of T. reesei in sugarcane bagasse with ( $(0)$ and without sucrose addition ( $\square)$.

\subsection{SSC with Consortium of $A$. niger and $T$. reesei in Sugarcane Bagasse}

The literature reports that the consortium of Trichoderma reesei and $A$. niger may lead to a supplement in terms of hydrolytic enzymes when compared to the cultivation of microorganisms separately, which would allow for greater use of substrates $[18,21]$. However, there is a gap in knowledge about the consortium of these fungi to obtain other bioproducts such as citric acid. Thus, results with the consortium are shown in Figs. (8-10) for conditions with and without the addition of sucrose. According to Fig. (9), provided with sucrose it was possible to obtain a maximum citric acid concentration of around $113 \mathrm{mg} \mathrm{L}^{-1}$ at 4 days of culture. This value is slightly higher than that obtained using only A. niger, suggesting that this fungus is primarily responsible for the production of citric acid. Moreover, the amount of glucose released into the fungal extract was lower than the cultivation where only $T$. reesei was inoculated, indicating that this phenomenon was hampered by the presence of another microorganism and competition by the amount of available glucose.

Again, the carbon profiles, nitrogen, moisture and $\mathrm{pH}$ of solid medium did not suffer considerable variations during the test period, highlighting the drop in $\mathrm{pH}$ after 48 hours for the cultivation with sucrose, at which point the citric acid production is intensified.

\subsection{Kinetic Parameters in SSC of $A$. niger and $T$. reesei from Sugarcane Bagasse}

As noted in previous sections, both carbon contents as glucose in the medium have a balance between consumption and production, which affects the estimates of income or conversion of these substrates into citric acid. Thus, the parameters may describe more reliably the crop productivity and specific rate of citric acid formation $\left(\mu_{\mathrm{p}}\right)$. For this, estimated biomass was carried out considering the empirical elemental formula of fungi [21] and the specific total nitrogen content. Thus, Table 1 shows the maximum Prod máx $_{\text {and }} \mu_{\mathrm{P}}$ for SSC in sugarcane bagasse with fungi in consortium and isolated. The results indicate that, for the isolated fungi, the higher productivity for $A$. niger is due to a higher amount of biomass, which leads to a lower $\mu_{\mathrm{p}}$. As citric acid is being partially linked to growth, the specific rates normalize this condition, since the productivity only considers the evolution of the product of interest over time. Thus, considering the results in Table 1, it is clear that the use of a fungal consortium was effective both in terms of productivity as a specific production and being more suitable for obtaining citric acid from sugarcane bagasse with added sucrose [21]. 


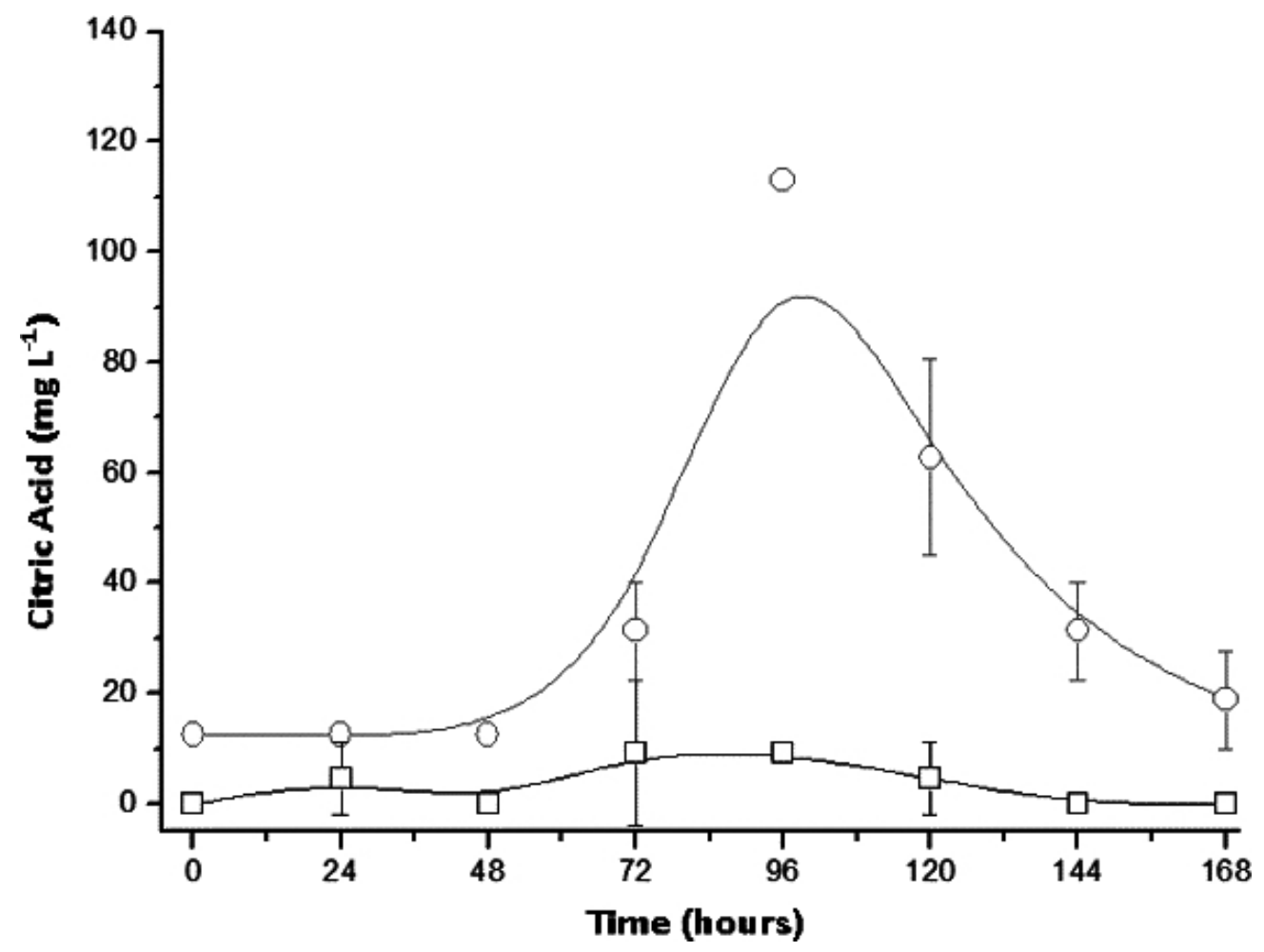

Fig. (8). Citric acid profiles during SSC of T. reesei and A. niger in sugarcane bagasse with (०) and without sucrose addition ( $\square$ ).

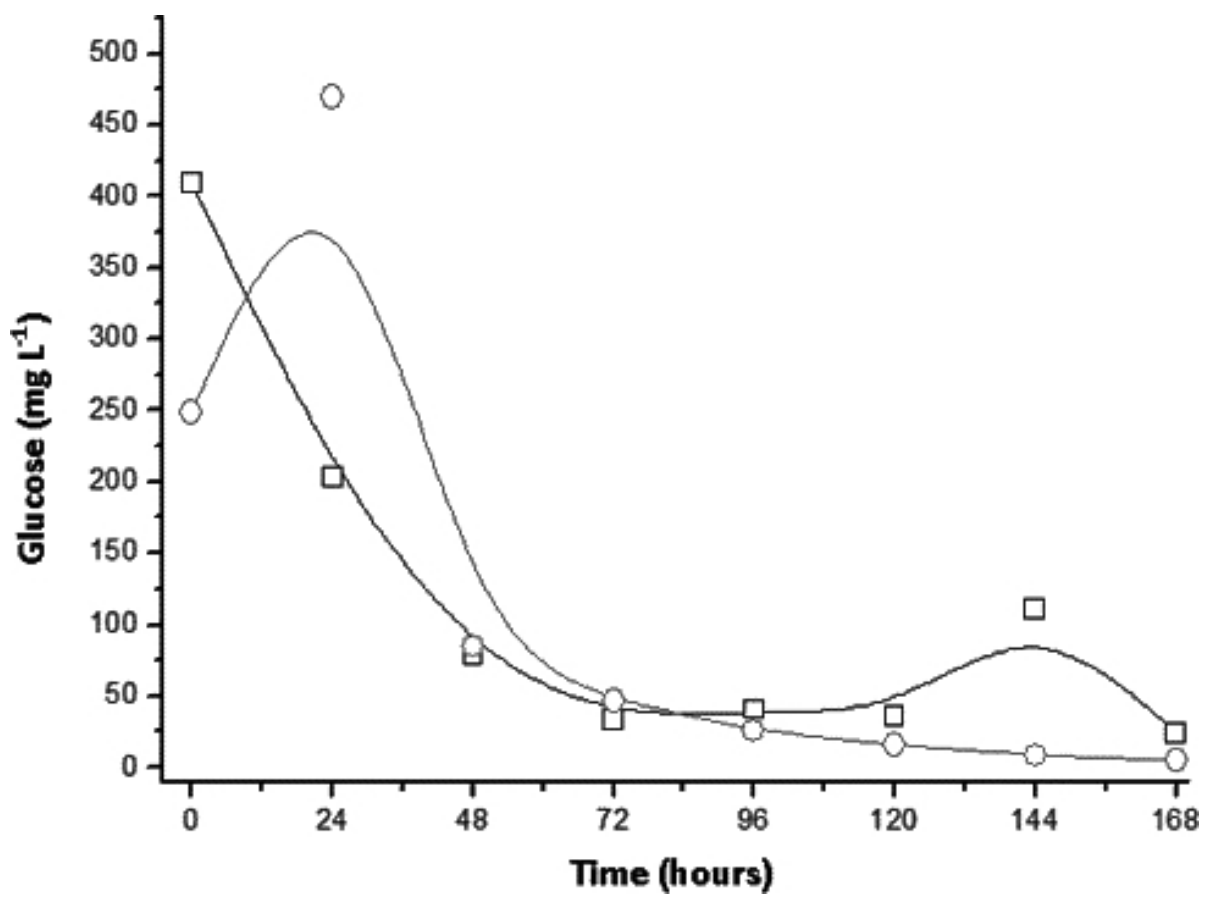

Fig. (9). Glucose profiles during SSC of T. reesei and A. niger in sugarcane bagasse with (०) and without sucrose addition (口). 


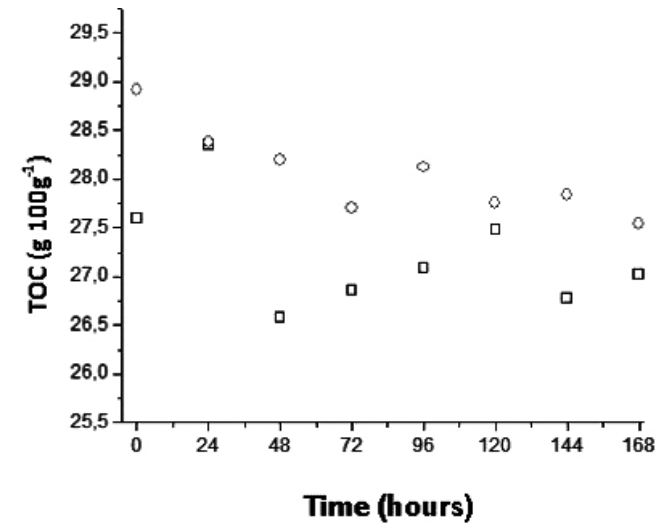

(A)

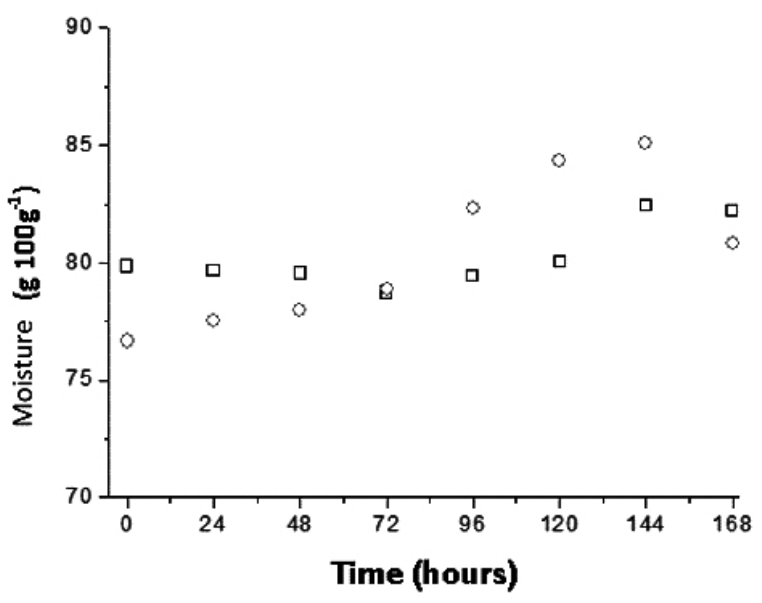

(C)

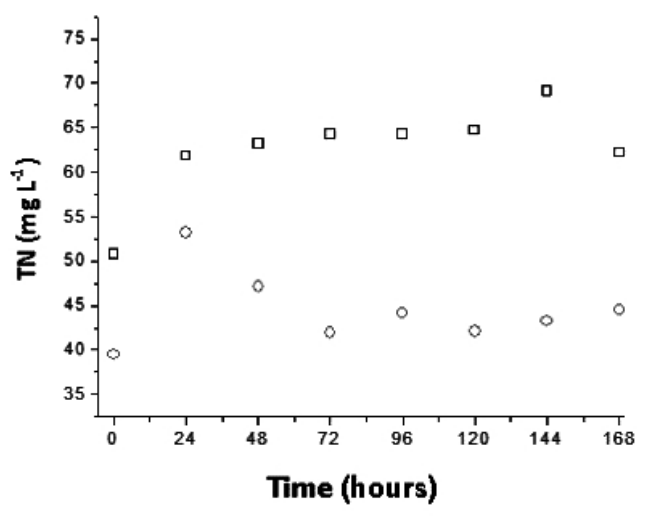

(B)

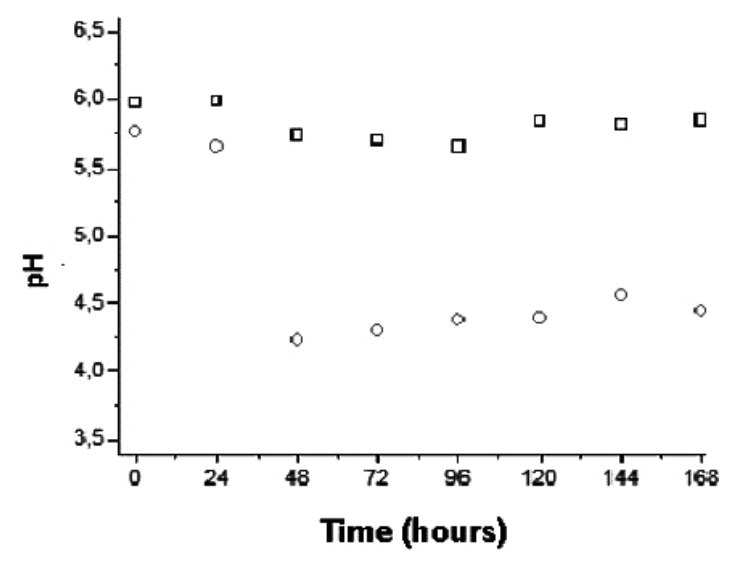

(D)

Fig. (10). TOC (A), TN (B), moisture (C) and pH of fungal extract (D) profiles during SSC of T. reesei and A. niger in sugarcane bagasse with ( $(\circ)$ and without sucrose addition ( $\square$ ).

Table 1. Maximum productivity (Prod ${ }_{\max }$ ) and maximum specific rates of citric acid production $\left(\mu_{\mathrm{P}} \max \right)$ for SSC in sugarcane bagasse with fungal consortium and isolated.

\begin{tabular}{|c|c|c|}
\hline Condition & $\begin{array}{c}\text { Prod }_{\text {max }} \\
\left(\mathbf{m g}_{\text {citric acid }} \mathbf{L}^{-1} \mathbf{h}^{-1}\right)\end{array}$ & $\boldsymbol{\mu}_{\mathrm{p}} \mathbf{m a x}{ }^{-1} \mathbf{m g}_{\text {citric acid }} \mathbf{g}_{\text {biomass }} \mathbf{h}^{-1}$ \\
\hline A. niger without sucrose & 1.08 & 1.72 \\
\hline T. reesei with sucrose & 0.72 & 2.30 \\
\hline Fungal consortium with sucrose & 1.18 & 2.51 \\
\hline
\end{tabular}

\section{CONCLUSION}

$A$. niger and $T$. reesei consortium led to the specific production of citric acid higher than that obtained when using the two fungi alone, indicating the complementation of hydrolytic enzymes of the fungi, allowing better use of sugarcane bagasse. The results improve the studies on solidstate cultivation, which have great technological potential, although they still lack basic and academic studies about citric acid production by the fungal consortium.
ETHICS APPROVAL AND CONSENT TO PARTICIPATE

Not applicable.

\section{HUMAN AND ANIMAL RIGHTS}

No animals/humans were used for studies that are the basis of this research.

\section{CONSENT FOR PUBLICATION}

Not applicable. 


\section{AVAILABILITY OF DATA AND MATERIALS}

Not applicable.

\section{FUNDING}

The authors are grateful for the financial support of Fundação de Amparo a Pesquisa do Estado de São Paulo (FAPESP), Brazil (Process Number 2016-09629-7) and the Coordenação de Aperfeiçoamento de Pessoal de Nível Superior (CAPES), Brazil, Finance Code 001”.

\section{CONFLICT OF INTEREST}

The author declares no conflict of interest, financial or otherwise.

\section{ACKNOWLEDGEMENTS}

None declared.

\section{REFERENCES}

[1] Pandey A. Solid-state fermentation. Biochem Eng J 2003; 13: 81-4. [http://dx.doi.org/10.1016/S1369-703X(02)00121-3]

[2] Gutiérrez-Correa M, Villena GK. Surface adhesion fermentation: A new fermentation category. Fermentación 2003; 10: 113-24.

[3] Pandey A, Soccol CR, Nigam P, Soccol VT. Biotechnological potential of agro-industrial residues. I: Sugarcane bagasse. Bioresour Technol 2000; 74: 69-80.

[http://dx.doi.org/10.1016/S0960-8524(99)00142-X]

[4] Hasan SDM, Gambale W, Zollner RL, Santana MH. Fungi allergens produced by solid-state fermentation process: Optimization and allergen characterization. Appl Biochem Biotechnol 2003; 105(108): 403-12.

[http://dx.doi.org/10.1385/ABAB:106:1-3:403] [PMID: 12721463]

[5] Menezes EA, Gambale W, Macedo MS, Abdalla DSP, Paula CR, Croce J. Biochemical, antigenic and allergenic characterization of crude extracts of Drechslera (Helminthosporium) monoceras Mycopathologia 1995; 131(2): 75-81.

[http://dx.doi.org/10.1007/BF01102882] [PMID: 8532058]

[6] Pandey A. Recent process developments in solid-state fermentation. Process Biochem 1992; 27: 109-17.

[http://dx.doi.org/10.1016/0032-9592(92)80017-W]

[7] Ahamed A, Vermette P. Enhanced enzyme production from mixed cultures of Trichoderma reesei RUT-C30 and Aspergillus niger LMA grown as fed batch in a stirred tank bioreactor Biochem Eng J 2008; 42: 41-468.

[http://dx.doi.org/10.1016/j.bej.2008.05.007]

[8] Bayer EA, Lamed R. The cellulose paradox: Pollutant par excellence and/or a reclaimable natural resource? Biodegradation 1992; 3(2-3):
171-88.

[http://dx.doi.org/10.1007/BF00129082] [PMID: 1369234]

[9] Kumar D, Jain VK, Shanker G, Srivastava A. Citric acid production by solid-state fermentation using sugarcane bagasse. Process Biochem 2003; 38: 1731-8

[http://dx.doi.org/10.1016/S0032-9592(02)00252-2]

[10] Stoilova IS, Gargova SA, Krastanov AI. Production of enzymes by mixed culture from micelial fungi in solid-state fermentation. Biotechnol Biotec Eq 2005; 19: 103-8.

[http://dx.doi.org/10.1080/13102818.2005.10817162]

[11] Dhillon GS, Brar SK, Kaur S, Verma MP. Bioproduction and extraction optimization of citric acid from Aspergillus niger by rotating drum type solid-state bioreactor. Ind Crops Prod 2013; 41: 78-84.

[http://dx.doi.org/10.1016/j.indcrop.2012.04.001]

[12] Khosravi-Darani K, Zoghi A. Comparison of pretreatment strategies of sugarcane baggase: Experimental design for citric acid production. Bioresour Technol 2008; 99(15): 6986-93.

[http://dx.doi.org/10.1016/j.biortech.2008.01.024] [PMID: 18334291]

[13] Vanderberghe LP, Soccol CR, Pandey A, Lebeault JM. Solid-state fermentation for the synthesis of citric acid by Aspergillus niger. Bioresour Technol 2000; 74: 175-8.

[http://dx.doi.org/10.1016/S0960-8524(99)00107-8]

[14] Bastos RG, Motta FL, Santana MHA. Oxygen transfer in solid-state cultivation under controlled moisture conditions. Appl Biochem Biotechnol 2014; 174(2): 708-18.

[http://dx.doi.org/10.1007/s12010-014-1101-1] [PMID: 25086924]

[15] Nielsen J, Villadsen J, Linden G. Bioreaction engineering principles. $2^{\text {nd }}$ ed. Plenum, New York: Kluwer Academic 2003.

[http://dx.doi.org/10.1007/978-1-4615-0767-3]

[16] Vandenberghe LPS, Soccol CR, Pandey A, Lebeault JM. Microbial production of citric acid. Braz Arch Biol Technol 1999; 42: 263-76. [http://dx.doi.org/10.1590/S1516-89131999000300001]

[17] Oliveira AF, Matos VC, Bastos RG. Cultivation of Aspergillus niger on sugarcane bagasse with vinasse. Biosci J 2012; 28: 889-94.

[18] Papagianni M. Advances in citric acid fermentation by Aspergillus niger: Biochemical aspects, membrane transport and modeling. Biotechnol Adv 2007; 25(3): 244-63.

[http://dx.doi.org/10.1016/j.biotechadv.2007.01.002] [PMID: 17337335]

[19] Lekanda JS, Pérez-Correa JR. Energy and water balances using kinetic modeling in a pilot-scale SSF bioreactor. Process Biochem 2004; 39: $1793-802$.

[http://dx.doi.org/10.1016/j.procbio.2003.09.001]

[20] Delabona PD, Pirota R, Codima CA, Tremacoldi CR, Rodrigues A, Farinas CS. Effect of initial moisture content on two Amazon rainforest Aspergillus strains cultivated on agro-industrial residues: biomass-degrading enzymes production and characterization. Ind Crops Prod 2013; 42: 236-42.

[http://dx.doi.org/10.1016/j.indcrop.2012.05.035]

[21] Yang YH, Wang BC, Wang QH, Xiang LJ, Duan CR. Research on solid-state fermentation on rice chaff with a microbial consortium. Colloids Surf B Biointerfaces 2004; 34(1): 1-6. [http://dx.doi.org/10.1016/j.colsurfb.2003.10.009] [PMID: 15261084]

(C) 2020 Bastos and Ribeiro.

This is an open access article distributed under the terms of the Creative Commons Attribution 4.0 International Public License (CC-BY 4.0), a copy of which is available at: (https://creativecommons.org/licenses/by/4.0/legalcode). This license permits unrestricted use, distribution, and reproduction in any medium, provided the original author and source are credited. 